form of the craters, as I might cail then, of the barmuic depressions, and their steepness in different directions.

'The following note has some comection with this inquiry, and I beg you, if you think it suitable, to give it a place in your esteemed journal :-

In 1874 I proposed to lay, as well as it can be done, a plane or planes, having such a slope as would represent the barometric height at some two distant places, and to indicate (in geodetic terms) the fall and strike, or the inclination on the horizon and the azimuth of the projection of the perpendicular on such a plane, and I still recommend it. In the Netherlands, where my area is small (see Jour. Scot. Met. Soc., iv, 25) it is always easy to find such a plane, and of course its perpendicular. Now I have inquired whether the projection of that perpendicular moved round the horizon generally in a direct way (with the sun) in the same manner as $M$. Dove has found that the direction of the wind does, and which I demonstrated in Pog S. Ann., Ixviii. 417, 553, to be the case thirteen times per annum in our latitude.

On examination $I$ find that in 1874 and 1875 the pro;ection has gone round the horizon in a direct way ten times more than the opposite way; furiher, that it often goes back when the direction of the projection lies to the south- $\leftarrow$ ast, but that when it has veered to be to the north.west it vecrs forward surely and quickly enough in a direct way to the east, which is in accordance with the fact that when we have a depression over Ireland or Scotland it then moves in the direction of Norway and Finland. I don't think it superfluous to call the attention of others to this research, and I propose to calculate the results for other years in this respect, which is easily cione by means of the Netherlands' Annumizes, and thus find thrice a day the direction and size of the steepest gradient.

Utrecht, December 23, 1876

Buys Ballót

\section{Mind and Matter}

THE problem, "How consciousness stands related to the material organism," has been attempted to be solved by $\mathrm{Mr}$. Duncan, under the liead of "Mind and Matter" (NATURs, vol, xv., p. 78\}. Now that a more exact scientific examinalion has reconciled so many differences on this question, a return to the old à priori method of mere logic is still perfectly legitimate, provided the losic is sound.

Admitting that consciousness is related to matter, and without contending, for the present, that it may not be a state of matter (under certain restrictions of the term), I will conterit nyself with pointing out what seem to be fallacies in this "solution." "It is as easy," says Mr. Duncan, "to predicate subjectivity (susceptibility to consciousness) of one entity called matter as of another entity ealled soul or spirit. It is no more difficult to conceive of matter being subjective than of spirit being subjective." Let us see if this is or is not petitio principii. It was the difficulty, real or apparent, of ascribing certain attributes (mental) to matter, that clemanded the supposition of some support other than material. So that when we say that spirit is alone susceptible to consciousness, we merely express that matter is not thus susceptible. Therefore, to affirm that the one may be as suscepible to consciousness as the other is to assume, in limine, that matter may be susceptible to conscionsness, the very probability which has to be established.

Mr. Duncan next asserts that "How energy is related to matter in all its forms, is no less mysterious than how subjectivity may be a property of matter." Now every opponent of materialism admits that how energy is related to matter is a mystery, and avows that he cannot conceive of consciousness as a proferty of matter; but the difficulty of understanding the hore, even if we grant it equal in both cases, cannot establish any parity of probability as to the facts; for while we know as a fact that energy is relat:d to matter, we do not know as a fact that subjectivity (susceptibility to conscionsness) is a property of matter. And even if we put the argument more exactly, and affirm that we know that subjectivity, like energy, is related to matter, stili nothing in point is gained, seeing that while we know all matter in relation to energy, it is only a certain form of matter (the human) which we knoiv to be related to subjectivity; for if we surmise this of a dog, we cannot know it till he tell us.

The next position, "Energy may be divided. Why not subjectivity?" would seem to demand nothing less than absolute proof, since subjectivity, or the state of the Ego, appears indivisible in virtue of its essential unity. Yet ro support is advanced except the foregoing assertion, which we have seen is a mere assumption on the side of materialism, and which we shall next see contrias a: admiscion all but fital to the cause it adrocates When Mr. Duncan says, "How energy is related to matter is no less mysterious than how subjectivity may be a property of matier," he admits that we cannot understand either, while he believes the first because it is a fact. But why should we believe the last? Because we cannot understand it, and because it is nest a fact? Will he admit that we have advanced any proof of an oyster being an astronomer, when we have affirmed that this wouid be no more mysterious than the relation of energy to malter? Yet his three remaining arguments go on this ground : they assume that the probability of subjectivity being a property of matter equals the fact of energy being related to matter.

Rugby

J. L. TUTPER

\section{Solar Physics at the Present Time}

AT the conclusion of his latter of the ist inst. (NArukg, vol. xv. p. 196), $\operatorname{Sir}(9$. B. Airy alludes to a paper of mine as being cited by me (in my last letter to NATURE) as being "in the "Philosoplical Transactions." "

The paper referred to ought, with little doubt, to have ap. peared there, but it did not, and I was most careful to avoid implying that it had; my words being wilh regard to it (see your pages 157 and 158$\}$ :-

Ist, "which I had the honour of communicating to the Rojal Society of London six years ayo ; " and

2nd, "that paper of six years ago, and still in the hands of the Royal Society ;"

nor is there any mention of the "Philosophical Transactions" throughout.

Edinburgh, Jannary 5 Astronomer Royal for Scotland

\section{Towering of Birds}

SNIPE frequentiy tower-malso pigeons. I saw a mailara that flew nearly hall a mile, towered, and, fell dead. Teal also tower, but their towering is different to the ordinary, as they are as often alive as dead when they tall. I have also remarked this in widgeons, and once in a prartridge. In the latter case birds fell right and left, the second a towerer. It was in heavy turnips that had been planted when mangel had missed. The towerer fell on an isolated mangel; when picked up, he was at least ten yards from the mangel and stili alive. Some years ago there was a discussion on this subject in Land and Watcr or the Fieth, and I think it was shown it was due to pulmonary hemorrhage. At least $I$ was quite aware of the cause, and that head or spine injuries had nothing to do with it.

Ovoca, Ireland

G. H. KinahaN

\section{Rooks Building at Christmas}

ON Christmas morning I saw a few raoks engaged in building in a clump of elms near my house. Four nests are now in pro. gress, though the gale of December 30 made the rooks desist from their work. During the ten years (about) that $\mathrm{I}$ have watched their proceedings, I think $I$ have never seen these birds begin building till February.

I may add that our well-watered lands and woods are being visited with wild duck, teal, peewits, and gulls in great numbers.

Valentines, Ilford, Essex

\section{Are We Drying Up?}

THE above question has been asked in the columns of NATURE. As a small contribution towards an answer, it may be stated that at this place the two last years, 1875 and 1876 , have been the two wettest in a series of twenty-four years.

In 1875 , the rainfall was $44^{\circ} 05$ inches. In $x 876$ 42.42,

The average of twenty-four years has been $33 \cdot 1 \mathrm{I}$ inches.

Clilun, January 7 GEORGE F. BURDER

\section{Radiant Points of Shooting Stars}

IN J)ecember, from observations of 163 shooting stars seen in $20 \frac{1}{2}$ hours' watching, chiefly in the evenings, I amply confirmed several of the positions of radiant points as given in my note (NATUks, vol. xv., p. 158 ), and observed that several of the showers there mentioned were actively continued. The centres, as I gave them, of two of these require revision, as the additional meteors seen in December indicate the radiants with 